\title{
Vectors of technical innovation delivery by small and medium Australian construction firms
}

\author{
Mary Hardie \\ School of Computing, Engineering and Mathematics, Western Sydney University, Australia
}

\begin{abstract}
Long-established Schumpeterian theory on innovation assumes that significant innovations are generated by large companies with ample spare resources. The allocation of time and money to speculative endeavours with unclear outcomes has often been regarded as beyond the scope of small and medium-sized enterprises (SMEs). As a result, authorities sometimes advise SMEs to concentrate on the adoption of existing innovative products and processes rather than the generation of new creative ideas. Despite this traditional wisdom, some very capable individuals actively choose to participate in the SME sector because the relative absence of internal bureaucratic processes and the capacity for agile response to changing circumstances. Ten case studies of significant technical innovations generated within construction SMEs were examined in the light of common themes identified through a literature review. The case studies were classified according to existing taxonomies of innovation. Content analysis was used to map the identified themes against the published material about the innovations from patent applications, company websites, trade literature and industry magazines. The findings indicate that SME innovation stems from several distinct motivations. These drivers of innovation can be described vectors. They inspire innovative solutions but the generated innovations also drive development towards solutions for other, quite different problems.
\end{abstract}

Keywords: Technical innovation, innovation generation, drivers, case studies, content analysis.

Paper type: Research article

\section{Introduction}

A business strategy focussing on innovation and continual improvement has long been identified as an effective means of ensuring ongoing financial success for businesses in a market economy (Schumpeter, 1934; Schumpeter, 1942; Tushman and Moore, 1988; Audretsch, 1995; Drucker 2002; Fagerberg, Mowery and Nelson, 2005). Increasingly, openness to innovation is also being associated with improved environmental and social performance in many sectors of the economy in a worldwide context. However some industry sectors, in particular, are widely reported to have avoided the challenge to adopt new attitudes and modes of operation (Reichstein, Salter and Gann 2005). Over several decades, the construction industry has been broadly criticised as slow to absorb both new management practices and new technologies (Bowley, 1966; Latham, 1994; Egan, 1998; Fairclough, 2002; Woudhuysen and Abley, 2004). Indeed, among the general public there is an often-reported perception of the construction industry as being 'dirty, dodgy and dangerous'.

In the Australian context, this belief was widely voiced in submissions to the Cole Royal Commission into the Building and Construction Industry (Cole, 2003). In his Summary of

\footnotetext{
Copyright: Construction Economics and Building 2016. (C) 2016 Mary Hardie. This is an Open Access article distributed under the terms of the Creative Commons Attribution 4.0 Unported (CC BY 4.0) License (https://creativecommons.org/licenses/by/4.0/), allowing third parties to copy and redistribute the material in any medium or format and to remix, transform, and build upon the material for any purpose, even commercially, provided the original work is properly cited and states its license.
}

Citation: Hardie, M. 2016. Vectors of technical innovation delivery by small and medium Australian construction firms, Construction Economics and Building, 16(3), 59-70. DOI: http://dx.doi.org/10.5130/AJCEB.v16i3.5158

Corresponding author: Mary Hardie; Email - M.Hardie@westernsydney.edu.au

Publisher: University of Technology Sydney (UTS) ePress 
Findings and Recommendations, the Royal Commissioner listed as his first report outcome that there was "an urgent need for structural and cultural reform" (Cole, 2003, p.3). In particular, the position of small contractors, subcontractors and independent workers was identified as highly vulnerable to disruption and intimidation because of their dependence on continuous and undelayed work to maintain cash flow and liquidity. Cole also identified "an unwillingness within industry leadership to recognise the long term advantages of structural and cultural change, accepting instead a short term project driven profit process" (Cole, 2003, p.13). In this context, the industry culture may be perceived by outsiders as belligerent, fractious, excessively competitive and even inwardly destructive. Risk shifting and blame shifting are reportedly commonplace and the smaller and more vulnerable end of the industry can be forced to carry the majority of the risk associated with introducing any new or improved practice (Zaghloul and Hartman, 2003; McGrath-Champ and Rosewarne, 2009). Significantly, the current contractual and governance system tends to assume this background environment of disputation, intimidation and lack of openness and access to information. The available remedies to the resulting disputes tend to be expensive legal ones and unfortunately smaller businesses often lack the capacity to defend their interests in the courts. As a result change from the bottom up may be stifled and a large part of the industry is deflected from the prospect of improving their individual situations through the introduction of an innovation strategy.

This negative picture does not, however, define the full range of activity and change management within the construction industry. Reforms to supply chains, procurement systems and quality control strategies have made significant improvements in industry performance in recent times (Briscoe et al., 2004; de Valence, 2010; Love, Irani and Edwards, 2004). Many leaders of construction firms are aware of the potential for industry disruption generated by digitalization and globalization. Industry veterans such as David Chandler OAM have warned of the need to adopt modern, measurable performance standards if the industry is to meet the challenge of the new era (Chandler, 2015). Construction SMEs have as much at stake as the large business sector and will need to demonstrate agility and innovation in response to new forms of competition and disruption.

\section{Literature review}

\section{SME definition}

The definition of what constitutes a Small and Medium Enterprise (SME) varies a great deal depending on the nature of the national economy and the industry sector concerned. Most definitions are based on number of employees though annual turnover, capitalisation and company structure are also included in some definitions (Loecher, 2000). In general, larger economies such as the United States of America set the maximum bar higher as regards inclusion in the category of SME. The Australian Bureau of Statistics (ABS) has its own definition which varies in the detail from the other definitions and is based on data collected through the system of Australian Business Numbers (ABNs).

The Australian Bureau of Statistics has been collecting specific data on SMEs since the early nineteen nineties. The definition of an SME has varied in the time since statistics were first separately kept. Initially 100 employees was the cut-off limit but since 2003 this has been raised to 200 employees. The SME sector is further subdivided as between 20 and 200 in medium business and up to 19 employees in small business with a further sub category of microbusinesses consisting of less than 5 employees. It is this definition that is accepted for the purposes of this study. While this means that comparisons to the collected data from other nations are limited by the different cut-offs, this is more than compensated for by the 
consistency of the government collected data. Year to year comparisons within Australia have a high level of validity due to the structural nature of how information is collected.

\section{Validity of SME information}

The introduction of the Goods and Services Tax (GST) in 2000 involved a system of national registration for all businesses delivering or using goods and services. The system involves the registration of the trading unit by an Australian Business Number provided by the Australian Taxation Office. Only businesses who earn total revenue of less than $\$ 50,000$ a year are exempt from this requirement and even some of them have an ABN nevertheless because it enables them to claim back GST amounts they have paid out to other businesses. As a result there are very reliable figures about the extent of business activity and a relatively small informal sector. In its Counts of Australian Businesses 2016, the ABS found that the construction industry had 339,367 businesses operating at the end of the financial year 2014-2015 (ABS, 2016). This figure would include sole operators, 'own account workers' and multiple trading identities operated by the same individual.

Since 2003 the ABS has specifically been collecting information on innovation in Australian business. In these data sets they define a business somewhat more rigidly than the Counts of Australian Business model. Businesses are only included in the innovation survey if they lodge Pay As You Go (PAYG) instalments with the Australian Tax Office. This means that sole traders who operate as a business with a separate business bank account from which they pay themselves wages are included in the survey. Sole operators who accept payment for work and deposit the receipts in their own private account are not included whether or not they later submit quarterly Instalment Activity Statements (IAS) or Business Activity Statements (BAS). There is a resultant large discrepancy in the number of businesses listed as operating in the construction industry in the Counts of Australian Businesses and in the Innovation in Australian Business Survey. For 2012-2013 the figures are 315,617 and 128,000 respectively. It can be seen that more than half the businesses in the construction industry operate in a fairly informal manner and employ few people.

\section{Nature of construction SMEs}

There are some known areas where SMEs are distinctly different from other industry participants. They often have very limited financial resources both in terms of capital and borrowings. As a consequence they often have little spare capacity to plan for change. They often have to contend with higher levels of competition than larger businesses; (Manley, 2008b). SMEs may be less able to monitor their competitors than large business. Consequently keeping an up to date technology watch may be beyond their resources unless they can do so through an industry network. Finally some SMEs may be motivated to simply survive rather than to grow (Abbott, Jeong and Allen, 2006). Both the risk and the cost of change may be too great for SMEs to attempt.

The positive side of SME situation is that many SMEs are headed by very able individuals who have chosen not to work in large business because of the brake that a large bureaucratic organisation can put on individual creativity. Such individuals have the potential to be leaders of enterprise growth and industry change, as well as being the generators of new systems and products. Nam and Tatum (1997) refer to them as 'champions' of innovation. The fact that the industry is characterised by many small businesses is therefore both its strength and its weakness. It does lead to restrictions on capacity and resources but it also enables creative individuals to move quickly in new directions and develop new solutions to industry problems. It is this potential that justifies this research into enabling factors for non-micro SME construction companies. 
Recent research has applied the concept of 'dynamic capabilities' in order to understand readiness and capacity for innovation (Gajendran et al. 2014; Gajendran, Brewer and Marimuthu, 2013; Brewer, Gajendran and Runeson, 2013). The dynamic capabilities framework enables introspection that allows firms to identify and seize opportunities for innovation by reconfiguring their resources to address changing circumstances. This provides insights as to how it may be possible for smaller firms to contribute to the innovation process without the spare capacity that Schumpeter considered axiomatic. Furthermore, Bröchner and Lagerqvist (2016) have pointed out the potential that partnerships with universities have to enable innovation collaborations. Such collaborations may lessen the disadvantage of SMEs in the innovation process.

\section{Taxonomies of innovation in construction}

Slaughter (1998) developed a technical innovation taxonomy which related to changes in both concepts and links. The five categories in ascending order from small change to large change are: Incremental; Modular; Architectural; Systems; and Radical. Using this taxonomy, the developers of innovations can become more aware of the changes that need to occur to deliver their innovation and consequently understand the level of intra-industry cooperation needed for successful adoption of a good idea in construction. Although the classifications represent a useful framework for discussing innovation, it should be remembered that innovation delivery is a complex process. An innovation that may be modular for one company in a supply chain may require systemic innovation for the users of the innovation (Harty, 2008). This complexity has been described by Afuah and Bahram (1995) as 'The hypercube of innovation'.

There are several other efforts to classify innovation in the literature. These include the decision making typology of Mitropoulos and Tatum (1999) which sorts innovation into two major categories; strategic/proactive versus project-based/reactive. There is also Gopalakrishnan and Bierly's taxonomy based on knowledge characteristics which has three general categories: Tacit/explicit, Systemic/autonomous; and Complex/ordinary (Gopalakrishnan and Bierly, 2001). This taxonomy, however, was explicitly created for organisational rather than technical innovation and as such is not strictly relevant to this study.

Harty (2005) described, the essential difference between a variety of innovation processes as consisting of whether they are bounded or unbounded. In other words, the critical aspect is whether or not the innovation has impacts beyond the operation of the innovator's own sphere of activity. Lim and Ofori (2007) taking a different tack found three classes of innovations: those that clients are willing to pay for because of their advantages for the end-user; those that reduce construction costs; and those produce competitive advantage through their intangible qualities. Each of these taxonomies of innovation are valid tools and will be used to classify the technical innovations case studies identified in this research, however, it is important to remember that technical innovation is essentially unique in each of its occurrences.

\section{Vectors of technical innovation}

This research is limited to the area of technical innovation rather than managerial or service innovations. The technical innovations studied relate to new building products, processes and equipment rather than organisational innovations. It is acknowledged that these categories are not exclusive and often occur simultaneously. This research aims to make a contribution to identifying some of the drivers that influence technical innovation delivery by SME construction firms.

Seven distinct themes or drivers were identified from the academic literature as having an impact on the generation of technical innovations in construction. These were: contractor creativity; client demands; solving problems on site; economic efficiency; environmental performance; 
work health and safety benefits; and end-user or social focus. These factors were then tested by content analysis against the available information on ten identified instances of technical innovation generation by SMEs. An explanation of the factors is described briefly below.

\section{Contractor creativity}

Slaughter (1993) looked in detail at the kinds of innovations developed by builders as opposed to component manufacturers and found that builders were not only more innovative in general, but that they generated the great majority of innovations that related to the connection or integration of component parts. As a result, it can be suggested that there exists a de facto design partnership between the component manufacturer and the builder which can lead to effective innovation delivery, if both sides recognise the necessity of acknowledging the constraints that affect the other's operations.

\section{Client demands}

That clients can play a key role in the delivery of innovation was recognised by Hislop (2002). Knowledgeable and supportive clients can foster innovative responses to construction problems provided that a mutually beneficial end result is delivered (Sexton and Barrett, 2005).

\section{Solving problems on site}

$\mathrm{Li}$ and Love (1998) looked at how construction problems should be identified, redesigned and solved. It was found that little formative or procedural knowledge is available about how this problem-solving is done. The problem can be defined as an 'unsatisfactory situation where conflicting properties and objectives coexist' ( $\mathrm{Li}$ and Love, 1998 p.724). In the complex and sometimes chaotic scenario of a construction site, such problems are frequently encountered. Experience assists with a creative response to a problem but only if there is openness to the process of unlearning past practices (Wong et al., 2011).

\section{Economic efficiency}

Abbott, Jeong and Allen (2006) found that the primary motivation for innovation by SMEs is overwhelmingly economic. Economic motivation encompasses such factors as basic survival, competitive advantage, overall profitability, market growth, reduction in the costs of production and market reputation.

\section{Environmental performance}

Gluch, Gustafsson \& Thuvander (2009) researched the absorbtive capacity of construction firms as a predictor of their readiness to incorporate 'green' innovations.

\section{Workplace Health and Safety benefits}

Both Lingard and Holmes (2001) and Loosemore and Andonakis (2007) have reported on the issues that relate to small construction businesses and construction safety innovations. While this is an area that some SMEs struggle with, it can also be a powerful incentive to embrace change because small business people are often very affected by the consequences of accident and injury in the workplace.

\section{End user or social focus}

While an economic focus is almost always present in construction innovations, some innovations find their primary motivation in improvements that are socially driven (Pemsel and Widén, 2010). This is particularly encouraged by a business focus on end-user satisfaction and resulting repeat business. In addition, safety innovations are often developed by industry practitioners 
who have experienced the impact of death or injury on site and are motivated to improve industry performance in this matter. Their motivation can be personal and deeply felt.

The vectors identified in the literature review are illustrated in Figure 1 below. Stemming from these potential vectors, the research question to be tested qualitatively in the case studies is "Does case study evidence support the significance of the identified vectors to SME innovators?"

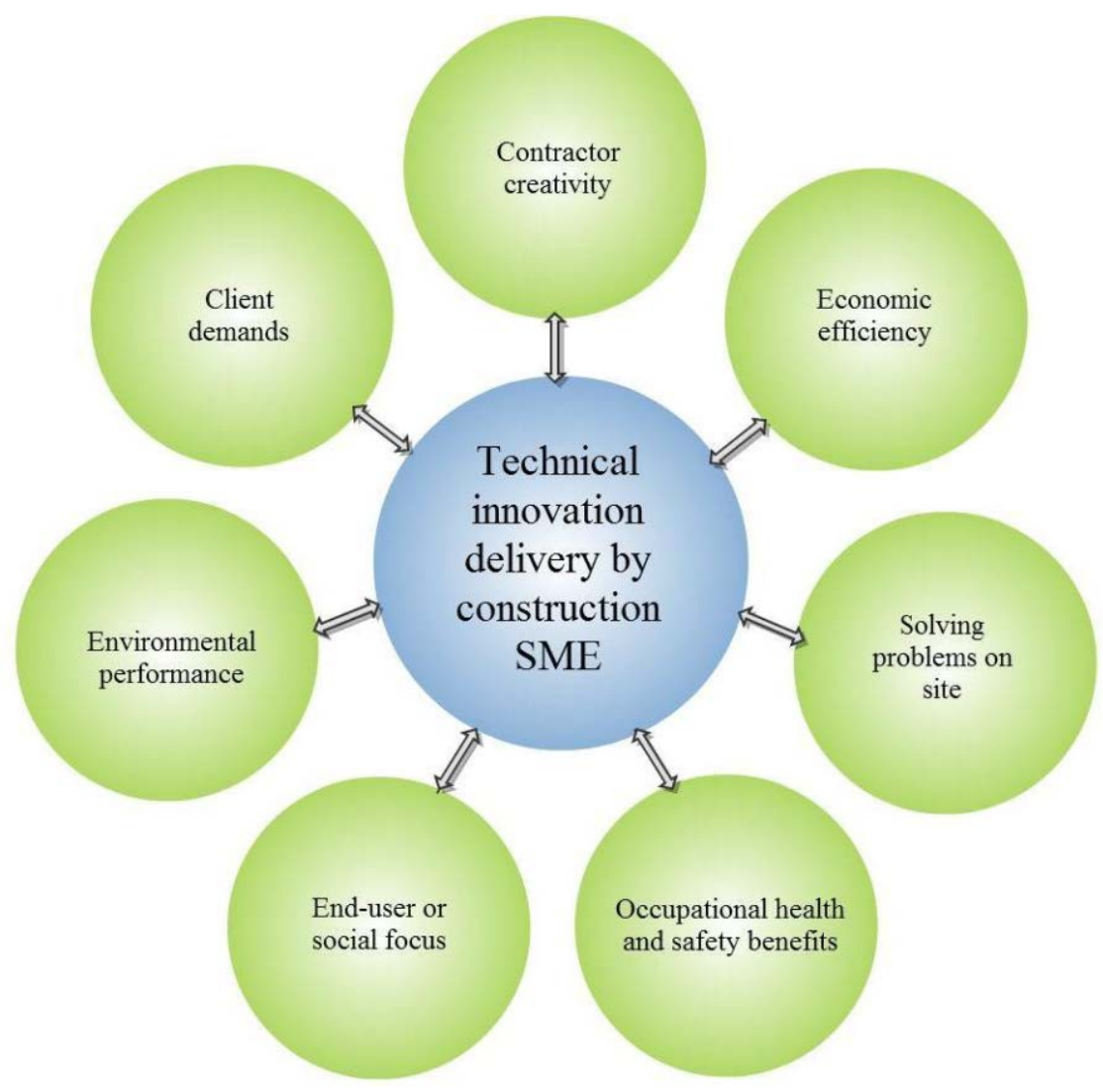

Figure 1: Vectors of technical innovation delivery

\section{Research method}

Purposive sampling techniques (Teddlie and $\mathrm{Yu}, 2007$ ) were used to select suitable technical innovation case studies. The intent of the case studies is descriptive rather than deterministic (Yin, 2009). The intention was to identify a select group of successful SME innovators and determine if they had any commonalities between them. The innovations studied were limited to building products, building processes and building equipment and did not include any service or managerial innovations. The principal criterion for inclusion in the case study list was a verifiable track record in successfully delivering a significantly original technical innovation. A significant technical innovation is defined in these circumstances as one that has received recognition by peers in the Australian construction industry.

The case studies were identified from several sources, which included public databases, industry awards and other peer recognition processes. Two public databases were used. These were Australian Technology Showcase (ATS) and the Building Research Innovation, Technology and Environment (BRITE) National Innovative Contractor Database. The ATS website is maintained by three Australian state governments (Queensland, New South Wales and Victoria), and is a national networking program aimed at promoting and developing export markets for 
innovative technology based products. The website covers products produced by SMEs from many industries, including more than 80 in construction. To be eligible, companies must provide two independent referee reports, a current business plan with a commercialisation strategy and they must demonstrate that their technology is: clearly innovative; scientifically credible; significantly local in content; commercially attractive; demonstrably marketable and exportable; and socially and environmentally beneficial (ATS, 2008).

A spreadsheet was assembled of 38 possible eligible case studies located in an area that was within a day's travel by car of the researcher's university home campus (approximately $150 \mathrm{~km}$ radius). While this geographic limitation could be seen as somewhat arbitrary, it should be noted that this region encompasses more than a fifth of the Australian construction industry by number of enterprises and, as such, may be regarded as a significant section of the national industry. It is not, of course, a random sample of the entire Australian construction sector, but this simply limits the generalisability of the results. It does not invalidate the usefulness of the sample as a view of opinions in a particular geographic zone.

Sufficient documentary material for content analysis was available from ten companies who had been identified as deliverers of a significantly original technical innovation. The evidence collected included patent documents listed on Scopus, company websites promoting the benefits of the technical innovation, industry award citations and trade literature. Table 1 describes the nature of the technical innovations studied and the classification of the company as small or medium sized. In addition, the case studies are classified according to whether or not they involve patented inventions or trade-marked intellectual property. Finally the degree of novelty is assessed.

\section{Content analysis}

The technique of content analysis was used to classify the data from the case studies. According to Krippendorff (2013, p xxii), context analysis views data not only as physical events but also as "texts, images and expressions that are created to be seen, read, interpreted and acted on for their meanings". Using content analysis to classify or code the frequency of themes in source documents allows for rich, multi-faceted interpretation which may yield useful insights into the nature of complex phenomena. Source documents, in this case include patents, product descriptions, webpage information, independent testing authority reports, magazine articles and award citations. Unstructured interviews were conducted with the principal innovator or innovation champion about the nature of their innovation and what were the factors that influenced its generation and delivery process. The case study data collection and interviews were undertaken between 2011 and 2014.

Source documents and unstructured interviews with the innovation champions were examined using content analysis techniques to identify correlations with the seven vectors of technical innovation identified through the literature review. Nvivo software was used to identify recurring themes in the source documents and interview transcripts. These are represented in Figure 1. The identified themes can properly be described as vectors because their relationship to the technical innovation can be either or both a push or pull effect.

\section{Results and discussion}

Table 2 summarises the initial classification of the innovations with respect to some of the taxonomic schemes reported from the literature. There are three polar pairs developed from the works listed: Strategic/Proactive/Top-down compared with Project-based/Reactive/Bottom-up (Mitropoulos and Tatum 1999); Bounded/Autonomous compared with Unbounded/Systematic (Harty, 2005); and Analytic/Rational compared with Intuitive/Behavioural (Gopalakrishnan and Bierly, 2001). There was a strong trend for the case studies to represent bounded innovations. 
This indicates that it may be easier for SMEs to innovate within a clearly defined area. They are less likely to be able to manage sufficient market share to require other businesses to alter their practices.

Table 1: Case study details

\begin{tabular}{llll}
\hline Technical innovation case study & Involves & $\begin{array}{l}\text { Involves } \\
\text { trademark } \\
\text { protected } \\
\text { intellectual } \\
\text { property }\end{array}$ & $\begin{array}{l}\text { Degree of novelty } \begin{array}{l}\text { Company } \\
\text { size by direct } \\
\text { employment }\end{array} \\
\text { inventions }\end{array}$
\end{tabular}

A. Lightweight interlocking concrete block, impervious to water that does not require tanking in retaining wall situations

$\begin{array}{cccc}\text { Yes } & \text { Yes } & \text { High } & \text { Medium } \\ \text { Yes } & \text { Yes } & \text { High } & \text { Small } \\ \text { Yes } & \text { Yes } & \text { Medium } & \text { Medium } \\ \text { No } & \text { Yes } & \text { High } & \text { Medium } \\ & & & \\ \text { Yes } & \text { Yes } & \text { High } & \text { Small }\end{array}$

B. Solar powered rainwater collecting hot water system for ridge line of roofs integrated with storage gutters at eaves

C. Early warning and function management system designed to reduce the risk of mobile plant roll over

D. Heavy lift tower cranes requiring minimal ground area at the base and suitable for restricted sites

E. Long span post tensioned steel roofs for column free internal space while minimising weight and materials usage

F. Increased use of recycled concrete as road base and aggregate in civil projects with tight scheduling requirements

G. Salt removing poultice to restore appearance and strength to masonry building components deteriorating due to salt deposits resulting from rising damp

H. Long span, lightweight, customised roof systems, including double curvature, fabricated on site for large structures such as airport terminals

Yes

High

Medium

I. Construction system for shoring walls in unstable soil conditions which can be used as close as $50 \mathrm{~mm}$ from an existing wall without underpinning

Yes

Yes

High

Medium

J. Road pavement repair system using a profiler machine to cut a $1 \mathrm{~m}$ trench along the edge of the road and fill with hot-mix to extend the life of the pavement without digging up large sections of roadway

Yes $\quad$ Yes $\quad$ Medium Medium

The great majority of the case studies were proactive rather than reactive. This probably indicates that SMEs who do manage to innovate are likely to be driven by a strong perception that their ideas are an improvement on current practice and should be incorporated as standard practice or "business as usual". There was a largely even split on the matter of whether the innovation was based on an analytic process or an intuitive one. This is surprising given the amount of 
investment involved in innovation delivery but may indicate the nature of inspiration which has to be followed by verification but is not always generated by an experimental process.

Table 2: Case study classifications

\begin{tabular}{|c|c|c|c|c|c|c|}
\hline 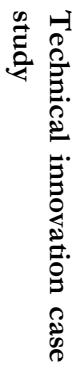 & 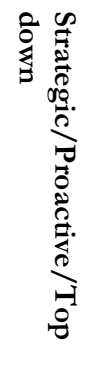 & 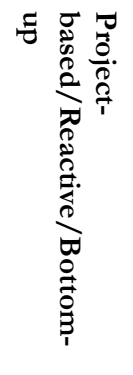 & 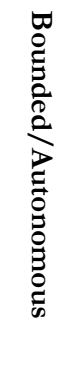 & 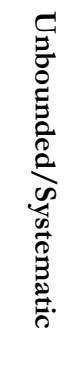 & 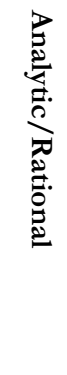 & 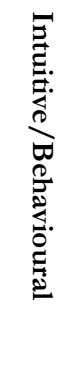 \\
\hline A. & $\checkmark$ & & & $\checkmark$ & & $\checkmark$ \\
\hline B. & $\checkmark$ & & $\checkmark$ & & & $\checkmark$ \\
\hline C. & & $\checkmark$ & $\checkmark$ & & $\checkmark$ & \\
\hline D. & $\checkmark$ & & $\checkmark$ & & $\checkmark$ & \\
\hline E. & $\checkmark$ & & & $\checkmark$ & $\checkmark$ & \\
\hline F. & & $\checkmark$ & $\checkmark$ & & & $\checkmark$ \\
\hline G. & $\checkmark$ & & $\checkmark$ & & & $\checkmark$ \\
\hline H. & $\checkmark$ & & $\checkmark$ & & $\checkmark$ & \\
\hline I. & & $\checkmark$ & $\checkmark$ & & & $\checkmark$ \\
\hline J. & $\checkmark$ & & $\checkmark$ & & & $\checkmark$ \\
\hline
\end{tabular}

Table 3: Vectors of SME technical innovation

\begin{tabular}{|c|c|c|c|c|c|c|c|}
\hline 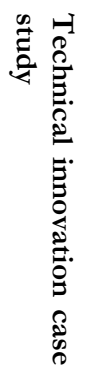 & 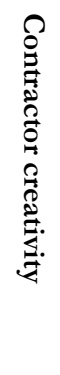 & 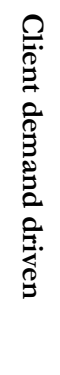 & 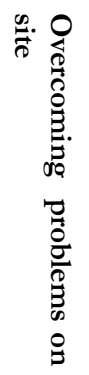 & 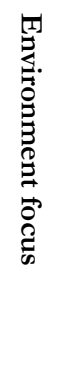 & 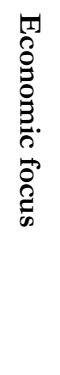 & 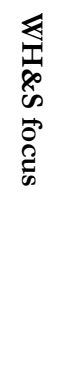 & 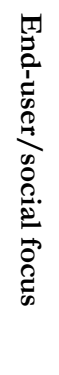 \\
\hline A. & $\checkmark$ & & $\checkmark$ & & $\checkmark$ & $\checkmark$ & \\
\hline B. & $\checkmark$ & & & $\checkmark$ & $\checkmark$ & & $\checkmark$ \\
\hline C. & $\checkmark$ & & $\checkmark$ & & $\checkmark$ & $\checkmark$ & \\
\hline D. & $\checkmark$ & & $\checkmark$ & & $\checkmark$ & $\checkmark$ & \\
\hline E. & $\checkmark$ & $\checkmark$ & & & $\checkmark$ & & \\
\hline F. & $\checkmark$ & $\checkmark$ & $\checkmark$ & $\checkmark$ & $\checkmark$ & & \\
\hline G. & $\checkmark$ & & $\checkmark$ & $\checkmark$ & $\checkmark$ & & $\checkmark$ \\
\hline $\mathrm{H}$ & $\checkmark$ & $\checkmark$ & & & $\checkmark$ & & $\checkmark$ \\
\hline I. & $\checkmark$ & & $\checkmark$ & & $\checkmark$ & $\checkmark$ & \\
\hline $\mathrm{J}$. & $\checkmark$ & & $\checkmark$ & & $\checkmark$ & $\checkmark$ & \\
\hline
\end{tabular}

Table 3 presents the alignment of the case study technical innovations with the identified vectors. All the case studies demonstrated evidence of contractor creativity and economic focus. 
This is perhaps unsurprising as the case studies were selected for their originality as well as for successful delivery of the innovation within the marketplace. Nevertheless, it is a useful finding in that it indicates that SME innovators require creative responses that are tempered with economic realism. The ability to seek a creative answer in response to a perceived problem without having to justify the expense to multiple levels of internal policy makers was mentioned directly or indirectly by the great majority of the lead innovators in each of the case studies. This is the justification that many give as to why they are comfortable in the SME situation.

Interestingly, three vectors were supported by the data on only a third of cases. These vectors were client demand, environment focus and end-user or social focus. While some of the innovators were highly aligned with these vectors, the clear majority were not aligned or only peripherally related to these vectors. Only half of the case studies in this study had a Work Health and Safety focus. Those that did support this vector, however, did so vehemently. Most of the case studies mentioned overcoming problems on site although they were more often proactive in response to these problems rather than reactive. In other words they anticipated these problems rather than responded to them.

\section{Conclusions}

As is the nature of much qualitative research, the findings are somewhat diverse. There is no clear theme that can be said to identify an SME generated technical innovation. Motivations and supports for innovation delivery appear to be closely related to the innovation character, as well as to the nature of the innovation champion. The SME sector in construction is large in number and diversified in nature. It is demonstrably possible for some SME champions to deliver significant technical innovations contrary to the expectations of traditional Schumpeterian theory. Whether overall innovation rates are improved by encouraging SME innovators is a question that remains to be addressed. This study answers the research question within the predetermined limitations of the study. Contractor creativity and economic motivation are the primary drivers for the innovators in this study. However, specific innovations may be driven by any of the identified vectors. No vector was unsupported by all the case studies.

The nature of this research is limited and descriptive rather than deterministic. It is important not to overstate the value of the conclusions. Further study on a much larger group of innovators may be able to draw firmer conclusions on the motivations and enablers of SME innovation. This would be significant for policy-makers as well as for aspiring innovators. In the meantime qualitative descriptions of the innovation delivery process have a useful role to play in shedding light on the process involved when new ideas are generated and brought to market by SME innovators.

\section{References}

Abbott, C. Jeong, K. and Allen, S., 2006. The economic motivation for innovation in small construction companies. Construction Innovation, 6(3), pp.187-96. doi: http://dx.doi.org/10.1108/14714170610710686

Afuah, A. and Bahram, N., 1995. The hypercube of innovation. Research Policy, 24(1), pp.51-76. doi: http://dx.doi.org/10.1016/0048-7333(93)00749-J

Audretsch, D.B., 1995. Innovation, Growth and Survival. International Journal of Industrial Organisation, 13(4), pp.44157. doi: http://dx.doi.org/10.1016/0167-7187(95)00499-8

Australian Bureau of Statistics, 2016. Cat. No. 8165.0: Counts of Australian Businesses, Including entries and exits, Jun 2011 to Jun 2015. Canberra: ABS.

Australian Technology Showcase, 2010. Australian Technology Showcase: Where Australian innovation meets the world. [online] Available at:< http://www.ats.business.gov.au/home > [Accessed 24 March 2016].

Bowley, M., 1966. The British Building Industry. London: Cambridge University Press.

Brewer, G. Gajendran, T. and Runeson, G., 2013. ICT \& innovation: A case of integration in a regional construction firm. Australasian Journal of Construction Economics and Building, 13(3), pp.2436.http://dx.doi.org/10.5130/ajceb.v13i3.3484 
Briscoe, G.H., Dainty, A.R.J., Millett, S.J. and Neale, R.H., 2004. Client-led strategies for construction supply chain improvement. Construction Management \& Economics, 22(2), pp.193-201. doi: http://dx.doi.org/10.1080/0144619042000201394

Bröchner, J. and Lagerqvist, O., 2016. From ideas to construction innovation: firms and universities collaborating. Construction Economics and Building, 16(1), pp.76-87.

Chandler, D., 2015. What Did the RICS Conference Mean for Construction's Future? [online] Available at: < https:// sourceable.net/2015-cobra-and-aubea-conference-was-all-about-the-future-of-construction-but-wasit/> [Accessed 24 March 2016].

Cole, T.R.H., 2003. Royal Commission into the Building and Construction Industry. Canberra: Australian Government.

de Valence, G., 2010. Innovation, Procurement and Construction Industry Development. Australasian Journal of Construction Economics and Building, 10(4), pp.50-9. doi: http://dx.doi.org/10.5130/ajceb.v10i4.1883

Drucker, P.F., 2002. The discipline of innovation. Harvard Business Review, 80(8), pp.95-100.

Egan, J., 1998. Rethinking Construction. London: UK Department of Environment, Transport and Regions.

Fagerberg, J., Mowery, D. and Nelson, R. eds., 2005. The Oxford handbook of innovation. Oxford, UK: Oxford University Press.

Fairclough, S.J., 2002. Rethinking Construction Innovation and Research: A Review of Government R\&D Policies and Practices. London: Department of Trade and Industry.

Gajendran, T., Brewer, G., Gudergan, S. and Sankaran, S., 2014. Deconstructing dynamic capabilities: the role of cognitive and organizational routines in the innovation process. Construction Management \& Economics, 32(3), pp.246-61. doi: http://dx.doi.org/10.1080/01446193.2013.845306

Gajendran, T., Brewer, G. and Marimuthu, M., 2013. Internationalisation of construction business and e-commerce: Innovation, integration and dynamic capabilities. Australasian Journal of Construction Economics and Building, 13(2), pp.11-22. doi: http://dx.doi.org/10.5130/ajceb.v13i2.3321

Gluch, P., Gustafsson, M. and Thuvander, L., 2009. An absorptive capacity model for green innovation and performance in the construction industry. Construction Management \& Economics, 27(5), pp.451-64. doi: http://dx.doi.org/10.1080/01446190902896645

Gopalakrishnan, S. and Bierly, P., 2001. Analyzing innovation adoption using a knowledge-based approach. Journal of Engineering Technology Management, 18, pp.107-30 doi: .http://dx.doi.org/10.1016/S0923-4748(01)00031-5

Harty, C., 2005. Innovation in construction: a sociology of technology approach. Building Research \& Information, 33 , (6), pp.512-22 doi: .http://dx.doi.org/10.1080/09613210500288605

Harty, C., 2008. Implementing innovation in construction: contexts, relative boundedness and actor-network theory. Construction Management \& Economics, 26(10), pp.1029 -41. doi: http://dx.doi.org/10.1080/01446190802298413

Hislop, D., 2002. The client role in consultancy relations during the appropriation of technological innovations. Research Policy, 33(5), pp.657-71. doi: http://dx.doi.org/10.1016/S0048-7333(01)00135-4

Krippendorf, K., 2013. Content analysis: An introduction to its methodology. 3rd ed. Los Angeles: Sage.

Latham, M., 1994. Constructing the Team. London: HMSO.

Li, H. and Love, P.E.D., 1998. Developing a theory for construction problem solving. Construction Management and Economics, 16(6), pp.721-7. doi: http://dx.doi.org/10.1080/014461998372015

Lim, J.N. and Ofori, G., 2007. Classification of innovation for strategic decision making in construction businesses. Construction Management \& Economics, 25(9), pp.936-78. doi: http://dx.doi.org/10.1080/01446190701393026

Lingard, L. and Holmes, N., 2001. Understandings of occupational health and safety risk control in small business construction firms: barriers to implementing technological controls. Construction Management \& Economics, 19(2), pp.217-26 doi: .http://dx.doi.org/10.1080/01446190010002570

Loecher, U., 2000. Small and medium-sized enterprises - delimitation and the European definition in the area of industrial business. European Business Review, 12(5), pp.261-4. doi: http://dx.doi.org/10.1108/09555340010373537

Loosemore, M. and Andonakis, N., 2007. Barriers to implementing OHS reforms - The experiences of small subcontractors in the Australian Construction Industry. International Journal of Project Management, 25(6), pp.57988. doi: http://dx.doi.org/10.1016/j.ijproman.2007.01.015

Love, P.E.D., Irani, Z. and Edwards, D.J., 2004. A seamless supply chain management model for construction. Supply Chain Management, 9(1), pp.43-56. doi: http://dx.doi.org/10.1108/13598540410517575

Manley, K., 2008. Against the odds: Small firms in Australia successfully introducing new technology on construction projects. Research Policy, 37(10), pp.1751-64. doi: http://dx.doi.org/10.1016/j.respol.2008.07.013

McGrath-Champ, S. and Rosewarne, S., 2009. Organizational change in Australian building and construction: rethinking a unilinear 'leaning' discourse. Construction Management and Economics, 27(11), pp.1111-28. doi: http://dx.doi.org/10.1080/01446190903236361

Mitropoulos, P. and Tatum, C.B., 1999. Technology Adoption Decisions in Construction Organizations. Journal of Construction Engineering and Management, 125(5), pp.330-8 doi: .http://dx.doi.org/10.1061/(ASCE)0733$\underline{\text { 9364(1999)125:5(330) }}$

Nam, C.H. and Tatum, C.B., 1997. Leaders and champions for construction innovation. Construction Management and Economics, 15(3), pp.259-70. doi: http://dx.doi.org/10.1080/014461997372999 
Pemsel, S. and Widén, K., 2010. Creating knowledge of end users' requirements: The interface between firm and project. Project Management Journal, 41(4), pp.122-30. doi: http://dx.doi.org/10.1002/pmj.20200

Reichstein, T., Salter, A. \& Gann, D., 2005, 'Last among equals: a comparison of innovation in construction, services and manufacturing in the UK', Construction Management and Economics, vol. 23, no. 6, pp. 631-44. doi: http://dx.doi.org/10.1080/01446190500126940

Schumpeter, J.A., 1934. The Theory of Economic Development. Cambridge, Mass: Harvard University Press.

Schumpeter, J.A., 1942. Capitalism, Socialism and Democracy. New York: Harper.

Sexton, M. and Barrett, P., 2005. Performance-based building and innovation: balancing client and industry needs. Building Research \& Information, 33(2), pp.142-8. doi: http://dx.doi.org/10.1080/0961321042000323789

Slaughter, E.S., 1993. Builders as sources of construction innovation. Journal of Construction Engineering and Management, 119(3), pp.532-49. doi: http://dx.doi.org/10.1061/(ASCE)0733-9364(1993)119:3(532)

Slaughter, E.S., 1998, 'Models of construction innovation.', Journal of Construction Engineering and Management, vol. 124, no. 3, pp. 226-31. doi: http://dx.doi.org/10.1061/(ASCE)0733-9364(1998)124:3(226)

Teddlie, C. and Yu, F., 2007. Mixed method sampling: A typology with examples. Journal of Mixed Methods Research. 1(1), pp.77-100. doi: http://dx.doi.org/10.1177/2345678906292430

Tushman, M.L. and Moore, W.L., 1988. Readings in the management of innovation. Boston, Mass: Ballinger Publishing Co.

Wong, P.S.P., Cheung, S.O., Yiu, R.L.Y. and Hardie, M., 2011. The unlearning dimension of organizational learning in construction projects. International Journal of Project Management, 30(1), pp.94-104. doi: http://dx.doi.org/10.1016/j.ipproman.2011.04.001

Woudhuysen, J. and Abley, I., 2004. Why Is Construction So Backward?, Chichester: John Wiley and Sons.

Yin, R.K., 2009. Case Study Research: Design and Methods. 4th ed. London: Sage.

Zaghloul, R. and Hartman, F., 2003. Construction contracts: the cost of mistrust. International Journal of Project Management, 21(6), pp.419-24. doi: http://dx.doi.org/10.1016/S0263-7863(02)00082-0 